\title{
Oil Contents and Aflatoxin Levels in Peanuts Varieties Produced in Busia and Kisii Central Districts, Kenya
}

\section{Menza C Nelson ${ }^{1 *}$, Muturi W Margaret ${ }^{1}$ and Kamau M Lucy ${ }^{2}$}

${ }^{1}$ Department of Medical Laboratory Sciences, Kenyatta University, Nairobi, Kenya

${ }^{2}$ Department of Zoological Sciences, Kenyatta University, Nairobi, Kenya

*Corresponding author: Menza C Nelson, Department of Medical Laboratory Sciences, Kenyatta University, Nairobi, Kenya, Tel: 2540725011570; E-mail: menza.nelson@ku.ac.ke

Received date: November 01, 2015; Accepted date: January 29, 2016; Published date: February 04, 2016

Copyright: ( 2016 Nelson MC, et al. This is an open-access article distributed under the terms of the Creative Commons Attribution License, which permits unrestricted use, distribution and reproduction in any medium, provided the original author and source are credited.

\begin{abstract}
Busia and Kisii Central districts have repeatedly reported high levels of aflatoxins in foods. The objectives of the study were to determine oil contents and the relationship between oil contents and the levels of total aflatoxin in peanuts varieties produced in the two districts. Three samples of each of the four (4) varieties of peanuts obtained from Busia; Valencia red, Uganda local, Homa Bay local and local red and 3 varieties from Kisii Central; Valencia red, Uganda local and Homa Bay local were analyzed and the average oil contents of the samples in each variety determined. The oil contents of peanuts were determined by a standard Soxtec extraction method and total aflatoxins were analyzed using high performance liquid chromatography (HPLC) technique. Peanuts from Busia district had significantly higher oil contents compared to those from Kisii Central $(t=3.22, d f=6, P=0.012)$. $P$ eanuts of Valencia red variety from both Busia and Kisii Central had higher oil content (mean 46.9), than other varieties. In addition, Valencia red from Busia district had slightly higher oil content $(47.2 \%)$ than those of the same variety from Kisii Central (46.6\%). However, the difference was not significant $(t=1.08, d f=6, P=0.394)$. Overall, oil content in peanuts decreased with an increase in aflatoxin levels ( $r=-0.496, P=0.031)$ except in peanuts of Uganda local red variety from Kisii Central. Growing of improved varieties of peanuts such as Valencia red which was least contaminated with aflatoxin and had higher oil content should be encouraged in Kenya.
\end{abstract}

Keywords: Peanuts; Oil contents; Levels of aflatoxins

\section{Introduction}

Aflatoxins are mycotoxin produced by Aspergillus species which grows in peanuts. Peanuts and peanuts oils are widely consumed in Kenya and peanut contamination with aflatoxins pose health risks to humans [1]. A large number of compounds originated from plants including essential oils from foods and microorganisms have been proven as strong inhibitors of aflatoxin (AF) biosynthesis [2]. Inhibition of growth and aflatoxin production by $A$. flavus and $A$. parasiticus by spice oils and their active components has been reported [2].

Studies towards identification of the target sites of these inhibitors have shown that they may act via interfering with the signal transduction regulatory networks involved in AF gene expression, blocking activities of AF biosynthetic cytosolicenzymes, downregulating fungal genes of the oxidative stress defense system that combats metabolic and environmental stressors. The oils also inhibit fungal pathogenesis factors, disrupting mitochondrial respiration, a critical process that provides acetyl-CoA for AF biosynthesis and they are also associated withmorphological alterations in the mycelium, such as vacuolation of cytoplasm and attenuation of cell wall [3]. This suggests that the integrity of the cell barriers particularly that of the cell wall, may be crucial in the regulation of aflatoxin production and excretion [3]. There are no studies documenting the effect of peanuts oil on growth of $A$. flavus and aflatoxin production in Kenya whereas such knowledge would be important in selection of peanut varieties for farming that are resistant to Aspergillus fungi that produces aflatoxin. The current study therefore evaluated the effect of peanut oils on growth of Aspergillus species and aflatoxin production in peanuts collected from Busia and Kisii Central districts.

\section{Materials and Methods}

\section{Study areas}

The study was conducted in two districts in western Kenya namely Busia and Kisii Central which represented Busia and Kisii counties respectively are the main peanut producing areas in Kenya [4] and have a high demand for peanuts and their products.

\section{Study design}

A cross-sectional study was adopted among the peanuts farmers in Busia and Kisii Central districts.

\section{Study population}

The study comprised of peanuts farmers in Busia and Kisii Central districts. The number of farmers growing groundnuts varied between different agro-ecological zones (divisions) within each district. The agro-ecological zones were determined based on altitude, mean annual rainfall, temperature and probability of successful growing of peanuts 
Page 2 of 5

in that zone. The peanuts production statistics of farmers were obtained from the division's agricultural offices [4].

\section{Sampling technique}

Peanuts farmers' households were sampled from the agro-ecological zones (divisions). In Busia, farmers in the leading groundnut producing divisions; Butula, Matayos, Funyula and Budalangi were purposively selected. The other division in Busia (Township) had only a small area under groundnuts cultivation was not included in the study. In Kisii, farmers in the four leading peanut producing divisions; Keumbu, Masimba, Suneka and Mosocho were also purposively sampled. The other divisions in the district (Kisii Town and Marani) were excluded from the study due to small areas under groundnuts production. Within the divisions selected in both Busia and Kisii Central districts, peanuts farmers households were randomly selected by staggering every fourth household within the division administrative boundary, the starting point being the fourth household from the division's agricultural office in the particular divisions. The sampling interval was obtained based on the approximate peanuts farmers' population of 408 in the study areas [5] divided by the sample size (102).

\section{Study approval, ethical consideration and informed consent}

Ethical approval was obtained from Kenyatta University Ethics Review Committee. The study objectives were explained to the peanuts farmers and they were allowed to ask questions. After giving consent, the participants signed a consent form and peanuts samples were collected. The participants were assured that information obtained would be treated with confidentiality.

\section{Laboratory Procedure}

\section{Sample collection}

A total of 204 peanut samples of different varieties were collected in the two districts using the procedure of Whitaker [6]. Peanuts stored in sacks or boxes were sampled from different parts using a closed spear driven through the top and sides of each sack or box to obtain a total of $0.5 \mathrm{~kg}$ of sample. Each of the $0.5 \mathrm{~kg}$ samples of unsorted peanuts were put in clean polyethylene bags, sealed, labeled and put in cool boxes. They were then transported taken to Bora Limited Laboratory, Nairobi and University of Nairobi, Department of Food Science, Nutrition and Technology and stored at $4^{\circ} \mathrm{C}$. In Busia district, the 102 peanuts samples were of four different varieties; Valencia red, Uganda local, Homa Bay local and Local red. The 102 peanuts samples from Kisii Central district were of three different varieties; Valencia red, Uganda local and Homa Bay local. In both districts, Valencia red variety had the most number of the samples, 59 and 89 from Busia and Kisii Central districts respectively which were significantly different from the other varieties $\left(\chi^{2}=12.00, \mathrm{df}=9, \mathrm{P}=0.02\right)$. There were more samples of Uganda local red (21) and Homa Bay local (20) varieties from Busia district compared to those from Kisii Central district. Local red variety had only 2 samples in Busia and none in Kisii Central (Table 1).

\begin{tabular}{|l|l|l|l|}
\hline \multirow{2}{*}{ Peanut Variety } & \multicolumn{3}{|c|}{ Number of peanut samples collected } \\
\cline { 2 - 4 } & Busia & Kisii Central & Total \\
\hline Valencia red & 59 & 89 & 148 \\
\hline Uganda local red & 21 & 5 & 26 \\
\hline Homa Bay local & 20 & 8 & 28 \\
\hline Local red & 2 & 0 & 2 \\
\hline Total & 102 & 102 & 204 \\
\hline
\end{tabular}

Table 1: Peanut varieties from Busia and Kisii Central districts.

\section{Aflatoxin analysis}

Each homogenized grounded peanut sample was triturated and analyzed to determine the types and levels of aflatoxin contaminants.

Extraction of aflatoxins from peanuts powder: Fifty grams from each homogenized peanuts sample was triturated in a blender in $50 \mathrm{ml}$ of $70 \%$ methanol $(70 \mathrm{ml}$ absolute methanol mixed in $30 \mathrm{ml}$ distilled water) containing $0.5 \%$ potassium chloride until thoroughly homogenized. The extract was transferred to a conical flask and centrifuged at $300 \mathrm{rpm}$ for 30 minutes to remove any particulates. The extract was filtered through Whatman No.4 filter paper and diluted 1:10 in phosphate buffered saline containing $500 \mu \mathrm{l} / \mathrm{L}$ Tween-20. Analysis for aflatoxins was done using High Performance Liquid Chromatography (HPLC).

Identification and quantification of aflatoxins: High Performance Liquid Chromatography was used to confirm identity of the aflatoxin and quantified using the method of Bragulat et al. [7]. HPLC system consisted of a Hewlett Packard 1100 pump (Palo Atto, CA, USA) connected to an HP 1046A programmable fluorescence detector and quantification was done with an HP workstation. Twenty microliters $(20 \mu \mathrm{l})$ of each extract was applied to HPLC and chromatographic separation was performed on a stainless steel C18 reversed phase analytical column $(150 \times 4.6 \mathrm{~mm}, 5 \mu \mathrm{m}$ particle size $)$ preceded by a $\mathrm{C} 18$ pre-column (Ultrasep $104 \mathrm{~mm}$ ). Water: methanol: acetonitrile (4:1:1, $\mathrm{v} / \mathrm{v} / \mathrm{v}$ ) was used as the mobile phase at a flow rate of $1.5 \mathrm{~mL} / \mathrm{min}$. Fluorescence of aflatoxin derivatives was recorded at excitation and emission wavelengths of $360 \mathrm{~nm}$ and $440 \mathrm{~nm}$ respectively. Aflatoxins were quantified based on HPLC fluorometric response compared with aflatoxin standards (Sigma chemical, St. Louis, MO, USA). The limit of detection was $0.005 \mu \mathrm{g} / \mathrm{kg}$ for AFB1 and AFG1, and $0.02 \mu \mathrm{g} / \mathrm{kg}$ for AFB2 and AFG2.

\section{Determination of oil contents of peanuts}

One sample from each of the four (4) varieties of peanuts collected from Busia and the 3 varieties of peanuts (Valencia red, Uganda local and Homa Bay local) collected from Kisii Central districts were analyzed for oil contents. The oil contents of peanuts were determined by a standard Soxtec extraction method using the procedure of Sundaram et al. [8]. Briefly, about 5 grams of the homogenized ground peanut sample was accurately weighed into an extraction thimble. The sample was then covered with cotton wool and the thimble was placed into the Soxtec extractor. A flat bottomed flask with $200 \mathrm{ml}$ of 
petroleum was placed on a heating mantle and connected to the Soxtec extractor and the extraction started. The extraction of oil continued for about 8 hours. After 8 hours, the solvent was evaporated in a rotary evaporator. The residue was then dried in an air oven at $105^{\circ} \mathrm{C}$ for 1 hour. The crude oil content of the sample was then calculated as a percentage by dividing the weight of the crude oil by the weight of the sample ( 5 grams), multiplied by $100 \%$.

\section{Data analysis}

The distribution of samples in the levels of aflatoxins was determined using Mann- Whitney $U$ test. The difference in oil contents of the different peanuts varieties from the two districts and the relationship between the oil content and the aflatoxin levels in the samples were determined using correlation test. All the statistical analysis was done using MINITAB and SPSS version 19.0 computer package.

\section{Results}

\section{Oil contents of the different varieties of peanuts}

Using a paired T-test, peanuts from Busia district had significantly higher oil contents compared to those from Kisii Central ( $t=3.22, \mathrm{df}=6$, $\mathrm{P}=0.012$ ). Peanuts of Valencia red variety from both Busia and Kisii Central had higher oil content (mean 46.9), compared to other varieties (Table 2). In addition, Valencia red variety peanuts from Busia district had slightly higher oil content $(47.2 \%)$ than peanuts of the same variety from Kisii Central which had $46.6 \%$ although the difference was not significant $(\mathrm{t}=1.08, \mathrm{df}=6, \mathrm{P}=0.394)$. Peanuts of Local red variety from Busia district had the lowest oil content $(42.7 \%)$ compared to other varieties from the same district $(t=2.28, d f=6$, $\mathrm{P}=0.026$ ). Homa Bay local variety peanuts from Kisii Central had the lowest oil content (40.6\%) among all the other peanuts varieties analyzed (Table 2).

\begin{tabular}{|c|c|c|c|}
\hline \multirow{2}{*}{ Peanuts variety } & \multicolumn{2}{|c|}{ Average (\%) } & \multirow[t]{2}{*}{ Overall Mean (\%) } \\
\hline & Busia & Kisii Central & \\
\hline Valencia red & 47.2 & 46.6 & 46.9 \\
\hline Uganda local red & 46.7 & 45.7 & 46.2 \\
\hline Homa Bay local & 43.2 & 40.6 & 41.9 \\
\hline Local red & 42.7 & - & 42.7 \\
\hline
\end{tabular}

Table 2: Oil contents of different varieties of peanuts from Busia and Kisii Central districts.

\section{Relationship between oil contents and the levels of total aflatoxin in peanuts}

Oil contents of peanuts from Busia and Kisii Central districts were compared with the total aflatoxins of the same samples. All the four peanuts varieties from Busia had lower levels of total aflatoxins except the Local red variety which had the highest total aflatoxins levels at 267 $\mu \mathrm{g} / \mathrm{kg}$ but with the lowest oil content average of $42.7 \%$ among peanuts varieties from Busia (Table 3). Peanuts varieties from Kisii Central had high levels of total aflatoxin but low oil contents. Peanuts of Uganda local red from Kisii Central had the highest total aflatoxin levels of 405 $\mu \mathrm{g} / \mathrm{kg}$ and average oil content of $45.7 \%$. Overall, there was an increase in total aflatoxin levels with decreasing oils contents $(r=-0.496$, $\mathrm{P}=0.031$ ) except in peanuts of Uganda local red variety from Kisii Central district (Table 3).

\begin{tabular}{|l|l|l|l|}
\hline \multirow{2}{*}{ District } & Peanut variety & $\begin{array}{l}\text { Average oil } \\
\text { content (\%) }\end{array}$ & $\begin{array}{l}\text { Total Aflatoxin level in } \\
\text { the sample }(\boldsymbol{\mu g} / \mathbf{k g})\end{array}$ \\
\hline \multirow{3}{*}{ Busia } & Valencia red & 47.2 & 2.3 \\
\cline { 2 - 4 } & Uganda local red & 46.7 & 2.4 \\
\cline { 2 - 4 } & Homa Bay local & 43.2 & 2.8 \\
\cline { 2 - 4 } & Local red & 42.7 & 267 \\
\hline \multirow{2}{*}{ Kisii Central } & Valencia red & 46.6 & 93 \\
\cline { 2 - 4 } & Uganda local & 45.7 & 405 \\
\cline { 2 - 4 } & Homa Bay local & 40.6 & 101.5 \\
\hline
\end{tabular}

Table 3: Oil contents in relation to total aflatoxins in peanuts analyzed.

Plotting oil content of peanut from Busia against Aflatoxin levels showed a reduction of oil content with increase in Aflatoxin levels $(\mathrm{r}=-0.0114, \mathrm{P}=0.051)$ and those from Kisii Central also showed decrease of oil contents with an increase in aflatoxin levels $(r=-0.0064$, $\mathrm{P}=0.045$ ) except Homa Bay local variety as illustrated in Figures 1 and 2 respectively.

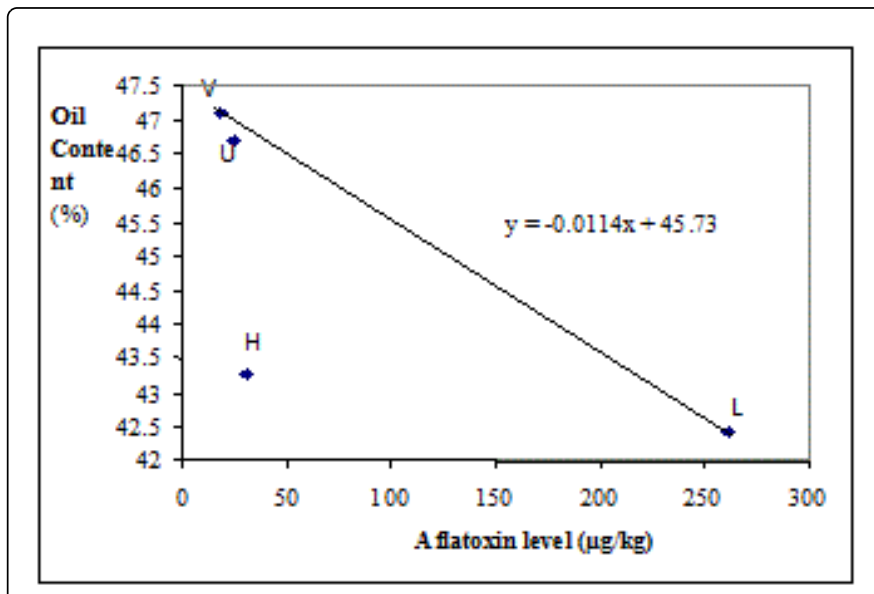

Figure 1: Relationship between Aflatoxin level with percentage oil content in peanuts from Busia district.

V=Valencia red; $\mathrm{U}=$ Uganda local red; $\mathrm{H}=$ Homa Bay local; $\mathrm{L}=$ Local red. 


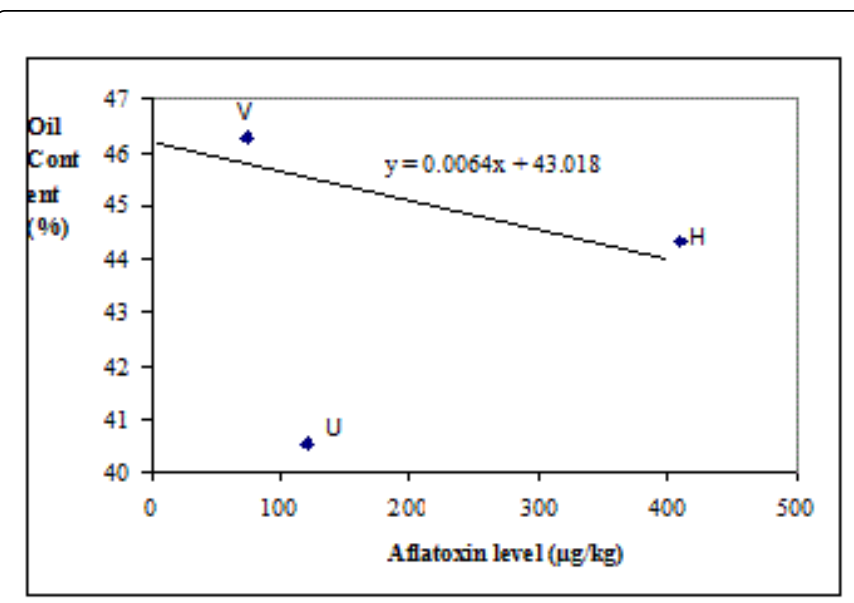

Figure 2: Relationship between Aflatoxin level with percentage oil content in peanuts from Kisii Central district.

$\mathrm{V}=$ Valencia red; $\mathrm{U}=$ Uganda local red; $\mathrm{H}=$ Homa Bay local.

\section{Discussion}

\section{Peanuts varieties from Busia and Kisii Central districts}

In both districts, peanuts of Valencia red variety had the highest number of samples, 59 and 89 from Busia and Kisii Central districts respectively which were significantly different from the other varieties. This could have been attributed by the fact that Valencia red variety is the most common improved variety of peanuts planted by farmers in the western region of Kenya [9] compared to other varieties in the study areas. The variety tends to be preferred due to higher yield and resistance to diseases which may also reduce their susceptibility to infection by Aspergillus species compared to the local varieties [9]. The result of this study is in line with that of Mutegi et al. [9] who documented a higher number of peanuts of Valencia red variety than the other varieties in the study areas.

In this study, there were few samples of peanuts of local varieties; Uganda local red (26), Homa Bay local (28) and Local red (2) from the two study districts. It is possible that peanuts farmers avoid planting these varieties because they have low yields and are less resistant to diseases [9]. Moreover, local varieties of peanuts such as Uganda local red, Homa Bay local and Local red, have been reported to be more susceptible to rosette virus and mould than improved varieties [4], and a positive correlation between the diseases and aflatoxin contamination of peanuts have been documented in other studies [11]. These findings are consistent with those reported in previous studies by Mutegi et al. [12].

\section{Oil contents of the different varieties of peanuts from Busia and Kisii Central districts}

Essential oils from foods and microorganisms have been proven as strong inhibitors of aflatoxin biosynthesis [1]. Inhibition of growth and aflatoxin production by Aspergillus flavus and $A$. parasiticus by spice oils has been reported [13]. In the current study, peanuts from Busia district had significantly higher oil contents compared to those from Kisii Central district $(t=3.22, \mathrm{df}=6, \mathrm{P}=0.012)$. This could be because the climate in Busia is hot and dry which enhances formation of oils compared to Kisii Central which is wet [9]. Being the first study to be conducted in Kenya to determine oil contents in peanuts, there is no data to be compared with the results of the current study. However, the result is in line with a previous study on peanuts done in Turkey [14].

Peanuts of Valencia red variety from both Busia and Kisii Central had higher oil content (mean 46.9), compared to other varieties analyzed in the study. This could probably be due to the fact that Valencia red is an improved peanut variety which takes shorter time to mature especially in dry climate and therefore very fast in the formation of oil compared to the other varieties analyzed. However, Local red variety peanuts from Busia and Homa Bay local from Kisii Central had the lowest oil content at $42.7 \%$ and $40.6 \%$ respectively. This could probably attribute to the longer time the local varieties take to mature compared to the improved varieties and therefore low formation of oil [13].

\section{Relationship between oil contents and the levels of total aflatoxin in the peanut samples}

Oil contents of peanuts from Busia and Kisii Central districts were compared with the total aflatoxins of the same samples. Overall, there was increased total aflatoxin levels with decreasing oils contents $(\mathrm{r}=-0.496, \mathrm{P}=0.031)$ except for Uganda local red variety from Kisii Central district. This is because low oil content in peanuts partially blocks activities of aflatoxin biosynthetic cytosolic enzymes hence increasing production of Aflatoxin production and vice versa. In addition, oils are known to disrupt fungal mitochondrial respiration that provides acetyl CoA for Aflatoxin biosynthesis and therefore the higher the oil content, the lower the Aflatoxin production by Aspergillus species [13]. The results are consistent with a report of a study done by Reddy et al. [13] who reported an increased inhibition of growth and production of aflatoxin by Aspergillus flavus and $A$. parasiticus by increased concentration of spice oils and their active components. Therefore, the higher the oils contents, the higher the inhibition of growth and production of aflatoxins by Aspergillus species.

As stated earlier, the only exception in the study was observed in peanuts of Uganda local red variety from Kisii Central district which had the highest level of total aflatoxins $(405 \mu \mathrm{g} / \mathrm{kg})$ compared with other varieties in the study. This variety also had high average oil content (45.7\%). The result could be explained by other factors other than oil content such as higher susceptibility of local peanuts varieties to crop diseases and pests that result in plant stress predisposing them to aflatoxin contamination [15]. Local peanuts varieties such as local red, Homa Bay local and Uganda local red have been reported to be susceptible to stem rot and mould [4] and a positive correlations between these diseases and aflatoxin contamination of peanuts have been reported [16]. The result is in line with the study of Mutegi et al. [12] who reported high aflatoxin levels in peanuts of local varieties compared to the improved ones.

Samples of all peanuts varieties from Busia had lower levels of total aflatoxins with an increase of oil content except the Local red variety. This variety had significantly higher total aflatoxins levels at $267 \mu \mathrm{g} / \mathrm{kg}$ and $42.7 \%$ average oil content. The result could probably be contributed by factors other than oil contents such as susceptibility to crop diseases and pests by local peanuts varieties that result in plant stress predisposing peanuts to growth and aflatoxin contamination by Aspergillus species. These results concur with the study of Hell et al. [10], who reported a positive correlation between the growing of local 
varieties and increased Aflatoxin levels in peanuts in Benin. Overall, peanuts from Busia district had high levels of oil contents and low level of total aflatoxins compared to those from Kisii Central which had slightly lower oil content and significantly higher total aflatoxins levels.

\section{Conclusion}

Valencia red peanut variety is manly grown in the two study areas. Oil content in different varieties of peanuts from Busia district was slightly higher than those from Kisii Central. However, the oil contents in peanuts decreased with an increase in aflatoxin levels $(r=-0.496$, $\mathrm{P}=0.031$ ) except peanuts of Uganda local red variety from Kisii Central. The study recommends further investigations on the link between oil contents and aflatoxins production by Aspergillus species as this was the first study to be carried out in Kenya.

\section{Acknowledgement}

We would like to thank Kenyatta University for payment of tuition fees and for the approval of this study. We also acknowledge the National Commission for Science, Technology and Innovation (NACOSTI), Kenya for issuing a Research permit for the study. We are grateful to all the peanuts farmers for their cooperation during sample collection.

\section{References}

1. Williams J, Phillips T, Jolly P, Stiles J, Jolly C, et al. (2004) Human aflatoxicosis in developing countries: a review of toxicology, exposure, potential health consequences, and interventions. American Journal Clinical Nutrition 80: 1106-22.

2. Tsigarida E, Skandamis P, Nychas GJ (2000) Behaviour of Listeria monocytogenes and autochthonous flora on meat stored under aerobic, vacuum and modified atmosphere packaging conditions with or without the presence of oregano essential oil at 5 degrees C. J Appl Microbiol 89: 901-909.

3. Ranasinghe L, Jayawardena B, Abeywickrama K (2002) Fungicidal activity of essential oils of Cinnamomum zeylanicum (L.) and Syzygium aromaticum (L.) Merret L. M. Perry against crown rot and anthracnose pathogens isolated from banana. Letters in Applied Microbiology 35: 208-211.

4. Ogwang T (2006) Status of groundnut production in Busia district: Lucrative legume Project. Stakeholders meeting, Milimani Resort, Kisumu.
5. Kipkoech A, Okiror M, Okalebo J, Maritim H (2007) Production efficiency and economic potential of different soil fertility management strategies among groundnut farmers of Kenya. Science World Journal 2: 51714-77951.

6. Whitaker TB (2006) Sampling foods for mycotoxins. Food Addit Contam 23: 50-61.

7. Bragulat MR, Abarca ML, Cabaes FJ (2001) An easy screening method for fungi producing ochratoxin A in pure culture. Int J Food Microbiol 71: 139-144.

8. Sundaram J, Kandala V, Holser A, Butts L, Windham R (2010) Determination of in- shell peanut oil and fatty acids composition using Near- Infrared Reflectance Spectroscopy. Journal of American Oil Chemists' Society 87: 1103-1114.

9. Mutegi CK, Ngugi HK, Hendriks SL, Jones RB (2009) Prevalence and factors associated with aflatoxin contamination of peanuts from Western Kenya. Int J Food Microbiol 130: 27-34.

10. Hell K, Cardwell K, Poehling H (2003) Relationship between management practices, fungal infection and aflatoxin for stored maize in Benin. Journal of Phytopathology 151: 690-698.

11. Udoh J, Cardwell K, Ikotun T (2000) Storage structures and aflatoxin content of maize in five agro-ecological zones of Nigeria. Journal of Stored Products Research 36: 187-201.

12. Mutegi C, Hendriks S and Ngugi H (2010) The Extent of Aflatoxin and Aspergillus Section Flavi, Penicillium Spp. and Rhizopus Spp. Contamination of Peanuts from Households in Western Kenya and the Causative factors of Contamination. Research Space 1: 1-107.

13. Reddy D, Thirumala-Devi K, Reddy S, Waliyar F, Mayo M, et al. (2002) Estimation of aflatoxin levels in selected foods and feeds in India. In Food Safety Management in Developing Countries. CIRAD-FAO Montpellier 6: 1-4.

14. Ozcan M, Serap S (2003) Physical and chemical analysis and fatty acid composition of peanut, peanut oil and peanut butter from ÇOM and NC-7 cultivars. Grasas y Aceites 54: 12-18.

15. Chapin J, Dorner J, Thomas J (2004) Association of a burrower bug (Heteroptera cydnidae) with aflatoxin contamination of peanut kernels. Journal of Entomological Sciences 39: 71-83.

16. Robertson-Hoyt LA, Betrán J, Payne GA, White DG, Isakeit T, et al. (2007) Relationships among resistances to fusarium and Aspergillus ear rots and contamination by fumonisin and aflatoxin in maize. Phytopathology 97: 311-317. 